\title{
Role of the Metabolic Minor Components in the Regulation of Intermolecular Interaction
}

\author{
Frida Gilmiyarova, Nataliya Kolotyeva, Viktoriya Radomskaya, Oksana Gusyakova, \\ Irina Gorbacheva, Valeriya Potekhina
}

Samara State Medical University, Samara, Russia

Email: bio-sam@yandex.ru

Received 5 June 2016; accepted 5 July 2016; published 8 July 2016

Copyright (C) 2016 by authors and Scientific Research Publishing Inc.

This work is licensed under the Creative Commons Attribution International License (CC BY).

http://creativecommons.org/licenses/by/4.0/

(c) (i) 0pen Access

\section{Abstract}

This work presents a study of intermolecular interactions using the model of the antigen antibody interactions of the $\mathrm{ABO}$ system. Absence of knowledge in the field of the $\mathrm{ABO}$ antigen's behavior as a biomolecule and the integration of these structures into cascade of metabolic and physiological processes create the conditions, which promote a successful using this new model in the future. Molecular recognition and designing are included into the main catalog of computer methods of research, which is called "in silico". Using PASS system, we describe the possible biological effects of pyruvate, lactate, antigen determinants $A$ and $B$. Pharmacological effects and molecular mechanisms of influence on activity of the factors regulating inside and intercellular interactions are predicted for such minor components as pyruvate and lactate. Due to variety of the biological effects, glycoproteins A and B are very perspective to study as biological active connections. The obtained knowledge proves that $\mathrm{ABO}$ antigens, as well as other glycoprotein conjugates are important mediators of intercellular adhesion and participants of signal transmission. Using ABO blood group system as a model helped to describe individual differences of parameters-degree and time of the agglutination beginning of antigen/antibody blood types of the $\mathrm{ABO}$-are revealed.

\section{Keywords}

Molecular Modeling, ABO Blood Group System, Lactate, Pyruvate, Intermolecular Interaction

\section{Introduction}

There is an intimate, yet poorly understood, link between cellular metabolic status, cell signaling and intermolecular interactions. That is why nowadays the question of fundamental research revealing the molecular mechanisms of the basic processes is especially important. Cell signaling is crucial in all major biological processes,

How to cite this paper: Gilmiyarova, F., Kolotyeva, N., Radomskaya, V., Gusyakova, O., Gorbacheva, I. and Potekhina, V. (2016) Role of the Metabolic Minor Components in the Regulation of Intermolecular Interaction. Journal of Biosciences and Medicines, 4, 28-35. http://dx.doi.org/10.4236/jbm.2016.47004 
it maintains the processes of synthesis and degradation, signal transduction, initiation of DNA replication, transcription, translation, proliferation, differentiation and adaptation. Each of these facts highlights the importance of our study. While many biochemical interactions that have been previously presented as a reaction consisting of proteins, enzymes, their substrates, we have lack of knowledge about the role of small molecules and natural metabolites in regulation of protein functions [1]-[3].

In the last decade, the study of protein interactions with small molecules, metabolites, in particular, was delayed in comparison with the study of other types of interactions such as protein-protein, protein-DNA and protein-RNA. Sporadic studies on the role of small molecules in regulation of protein function were first released only in 2009 [4] [5]. With regards to the participation of natural metabolites (small molecules) and protein-protein interaction, this field was not studied previously and now it is the object of our study. Due to the achievements of the technical and scientific progress now, we are standing on the new level of studying intermolecular interactions [6]. Long-standing ideas portrayed lactate and other minor metabolites in a negative context as dead-end metabolites; we can trace that pattern throughout the history of biochemistry and physiology. Moreover, waving concentrations of lactate and pyruvate are typical for the number of pathologies [7]-[11].

The aim of this study is to provide molecular modeling and metabolic sensing using biogenic molecules of low molecular weight (pyruvate and lactate) and to determine the role of natural intermediates in the processes of protein-ligand interactions.

\section{Materials and Methods}

The object of the study was the molecular AB0 blood system model. Using that model we studied the effects of natural metabolites (pyruvate and lactate) on antigen-antibody interaction [12]. The control was the average value of time (in seconds) and the degree of agglutination of the antigens A and B (on a scale) II, III, IV groups of blood with monoclonal antibodies. To determine biological effects of small molecules on the agglutinogens A and $\mathrm{B}$, natural isoagglutinin anti-A and anti-B of the $\mathrm{AB} 0$ blood group system and monoclonal antibodies anti-A and anti-B before the start of hemagglutinating reaction erythrocytes were treated with lactate and pyruvate in a final concentration of $2 \mathrm{~mm}$ [13].

Blood typing was performed using Anti-A, Anti-B monoclonal antibodies by direct agglutination test. Agglutination was calculated by W. Marsh with indication of degree of agglutination [14]. Blood typing was also performed using an automated analyzer for immunoresearch Hemos SP II BioRad, USA.

Visualization of protein-protein complexes was conducted using an experimental stand, which is based on the confocal optical microscope Olympus IX 71 (Olympus, Japan), a confocal scanning unit and a laser unit (firm ANDOR); as well as on flow cytometer FACS Calibur Beckton Dickinson company (USA), using specific conjugated monoclonal antibodies labeled with fluoresceinisothiocyanate (FITZ) company Santa Cruz biotechnology, Inc. (USA).

Computer prediction of the spectrum of pyruvate and lactate biological activity was performed by the computer system known as Prediction of Activity Spectra for Substances (PASS) based on the structural formula of the compound of interest. In the PASS program results of prediction of biological activity spectrum are shown as an ordered list of the names of corresponding activities and the probability Pa ("to be active") and Pi ("to be inactive"), which are functions of the statistical values for the analyzed compound. Since we have investigated the molecule of known structure, the optimal probability value for the presence of certain biological activities was considered as $\mathrm{Pa}>0.5$ [15].

Statistical analysis was carried out using a statistical software package SPSS 12.0, ANOVA and the program MS EXCEL 2007.

\section{Results}

\subsection{Lactate and Pyruvate Computer Modeling}

Pointing out some of important effects (Figure 1(a)), we would like to attract your attention to the ability of pyruvate and lactate to influence the processes of maturation of cells: stimulating the leukopoiesis and the erythropoiesis, to exert immunomodulatory, anti-inflammatory, antineurotoxic actions. Furthermore, small molecules can provide a protective effect on the membranes of the cells and blood vessels. Probably, the realization of this effect depends on neurogenic tone of blood vessels [16]. Indicates the ability of lactate to exercise fibrinolytic, antitoxic effects. The ability of lactate to exert such biological effects, is presumably related to the constitu- 


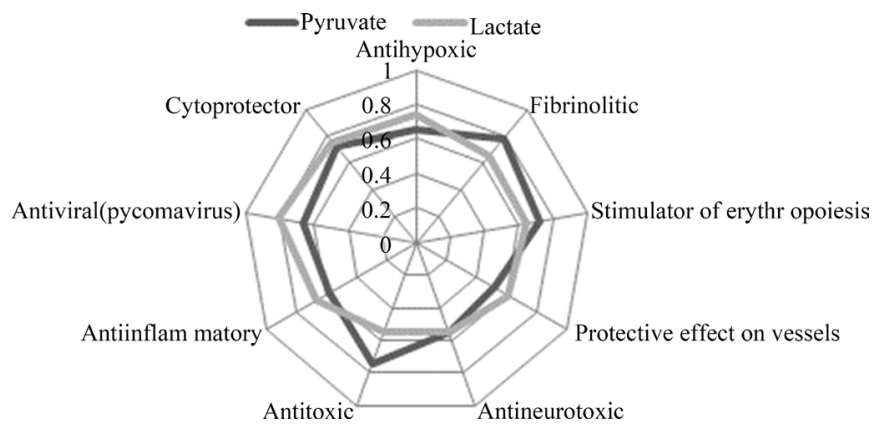

(a)

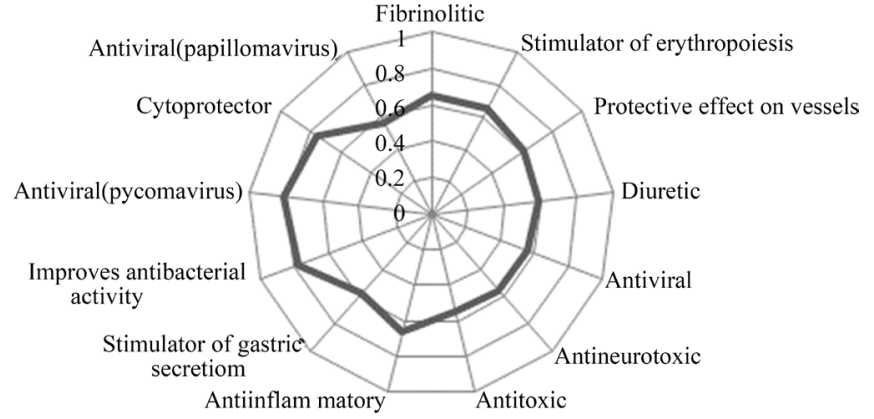

(b)

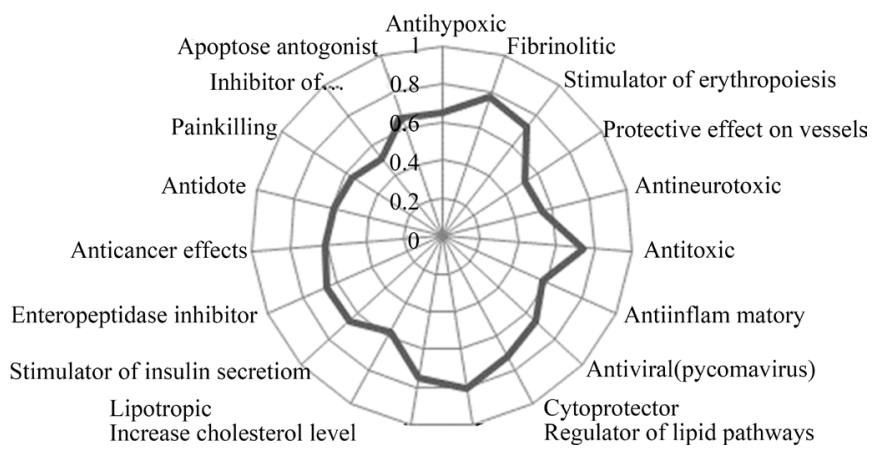

(c)

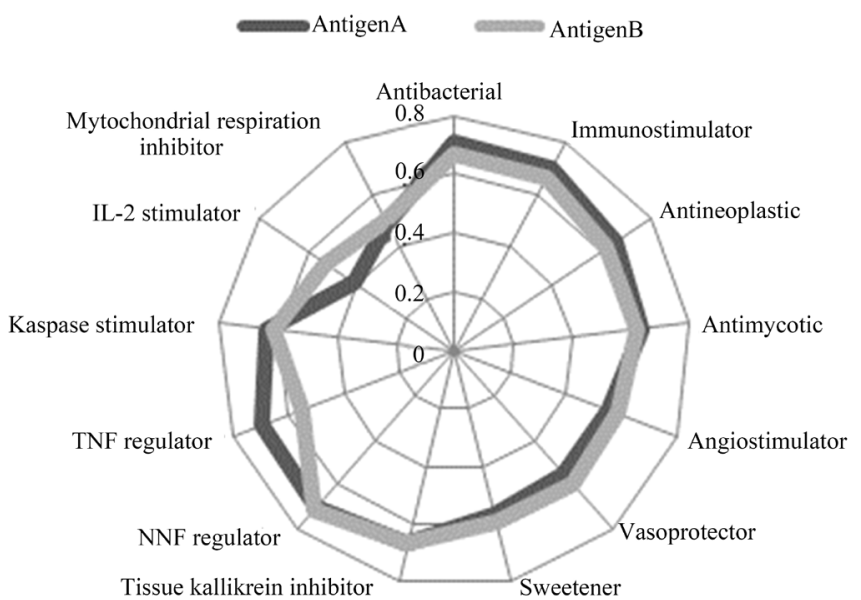

(d)

Figure 1. (a) The predicted spectrum of biological effects of pyruvate and lactate; (b) The predicted spectrum of biological effects of lactate; (c) The predicted spectrum of biological effects of pyruvate; (d) The predicted spectrum of biological activities of $\mathrm{A}$ and $\mathrm{B}$ antigens. 
ent hydroxyl group, which allows to take part in reactions of nucleophilic substitution.

In addition, we have observed the influence of lactate and pyruvate on antioxidant systems of the body, in particular-superoxide dismutase. Both act as an inhibitor of this enzyme, lactate and pyruvate are able to slow down the process of protecting cells from reactions of free radical oxidation, which constantly flow in the body, creating conditions for oxidative stress, damage molecules and structures.

Assessing the biological effects of lactate (Figure 1(b)), we found the ability to potentiate antibacterial activity, antiviral effect against arboviruses, rhinoviruses, picornaviruses and papillomaviruses. Antiviral activity of lactate is presumably associated with $\mathrm{pH}$-dependent rearrangements in the structure of the virus: with decreasing $\mathrm{pH}$, the virus loses its infectious activity, the connection of ribonucleoprotein with the protein matrix increases, which prevents the replication process [17]. Interesting was data that lactate was a promoter of insulin synthesis, thus clearly supporting the required amount of this hormone in the blood.

As for pyruvate (Figure 1(c)), it revealed the ability to act as a regulator of lipid metabolism, inhibitior of thrombocytopoiesis, to cause geroprotecting effect, to provide analgetic, anti-carcinogenic actions. Significantly, pyruvate participates in the process of tissue respiration, inhibits L- and D-forms of lactate dehydrogenase cytochrome. Pyruvate can be an oxidizer, an inhibitor of acylglycerols and a regulator of lipid metabolism, to increase cholesterol level and to reveal lipotropic effects.

The next step was to elucidate the potential biological activity of the antigens defined by the structural characteristics of the antigenic determinants of the ABO system (Figure 1(d)). To implement this task, we again used the computer program PASS. While studying the antigen A with $\mathrm{N}$-acetylgalactosamine as a terminal monosaccharide and $\mathrm{B}$ antigen with galactose, obvious quantitative and qualitative differences of the identified effects and mechanisms for their realization were found.

An antigen determinant B has 106 pharmacological effects, performing with 311 molecular mechanisms of action. The number of side effects decreased to 16, metabolic activity increased, regulatory effect on gene expression still remains low, but increased in 1, 5 times comparing with A antigen. Probably this difference is the basis of selective affinity to antigens and foreign molecular, which appears in different incidence between 0 (I)-AB (IV) blood groups.

However, the results obtained by computer simulation are not the same as status vivo. Determinants of oligosaccharide chains of the ABO system, presented on the membranes of all cells of the body, might have multifunctionality and capacity to multiple effects on vital processes, maintaining the purity of our endoecology and providing a dynamic homeostasis along with other factors.

\subsection{Effects of Lactate and Pyruvate on Antigen-Antibody Interaction}

After examining in silico the potential of natural metabolites and antigenic determinants, we passed to the series of model experiments. Influence of pyruvate and lactate on the antigen-antibody complexes AB0 system was carried out considering changes of degree and speed of onset of agglutination. We found that the second blood group was the most sensible to the effects of pyruvate and lactate- the time of agglutination onset increased by $16 \%$ and $40 \%$ respectively. Antigen determinant $A$ of the fourth blood group is more sensible to the influence of external stimules in contrast to the glycoprotein B. The degree of agglutination of the antigens of A (II)-B (IV) blood groups remained stable comparing with the control and amounted 4+. In general, we note that lactate influences more than pyruvate on the A and B determinants: formation of complexes antigen-antibody was longer (Figure 2(a)). Red blood cells A (II) and AB (IV) groups which have glycoprotein A on the surface, slower engage with the monoclonal antibodies than $\mathrm{B}$ (III) and $\mathrm{AB}$ (IV) blood groups on the membrane which have antigenic determinant agglutinogen $\mathrm{B}$.

We can see a different effect of pyruvate and lactate in contacting with natural antibodies (Figure 2(b)). It is shown that the effect of lactate on whole blood system causes a modification of the immunoglobulins in plasma. There is a reduction in the degree of agglutination of the natural anti-A and anti-b antibodies with corresponding antigens compared to the control value.

Various impacts of pyruvate and lactate preincubation with monoclonal antibodies were discovered (Figure 2(c)). Lactate caused the deterioration of monoclonal antibodies recognizing antigenic determinants A and B A (II)-B (IV) blood groups, slowing down the formation of antigen-antibody complexes 20 and 15 times, as well as the severity of the degree of agglutination of $75 \%$. Based on the obtained data, it can be assumed that incubation with lactate leads to structural and functional changes due to high chemical activity of the hydroxy acids, 


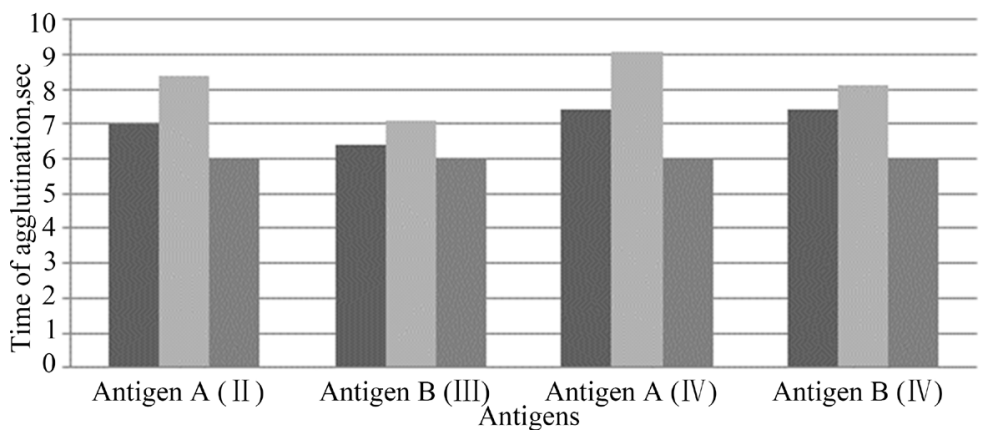

(a)

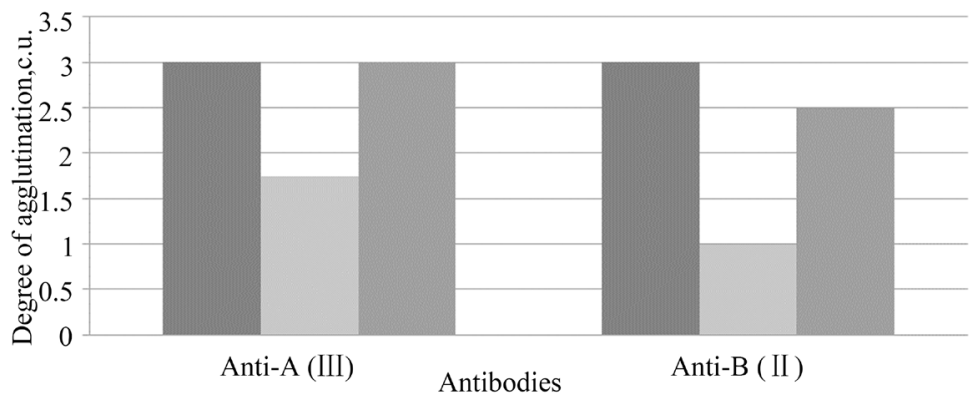

(b)

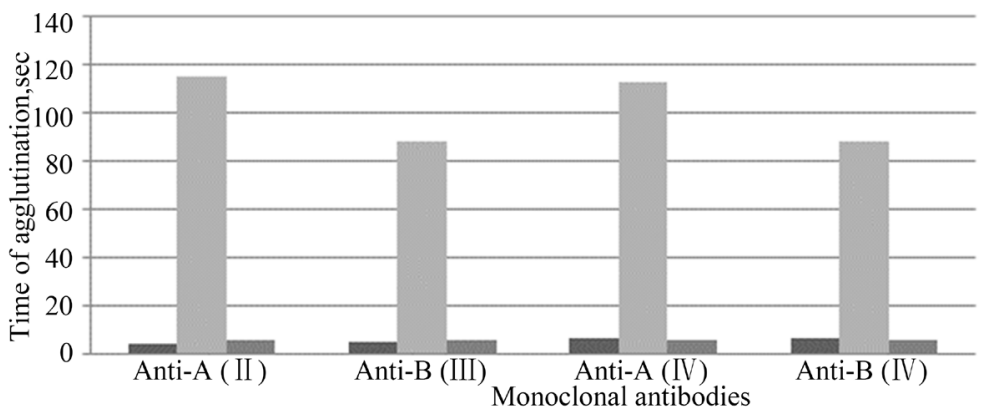

(c) myruvate

- Lactate

antrol

vate

Lactate

-Control

\section{-Pyruvate}

=Lactate

acontrol

Figure 2. (a) Effects of lactate and pyruvate on antigens AB0 blood system; (b) Effects of lactate and pyruvate on anti-A, anti-B antibodies of AB0 blood system; (c) Effects of lactate and pyruvate on anti-A, anti-B monoclonal antibodies.

the presence of a negative charge. We consider it is connected with non-enzymatic interactions. The time of agglutination of anti-A and anti-B monoclonal antibodies, preincubating with pyruvate decreased comparing with the control. In the interaction of anti-A and anti-B monoclonal antibodies with red blood cells of AB (IV) blood group-time interaction with the antigens A and B increased. The relative standard deviation (RSD) for each experiment result was evaluated (Table 1 and Table 2). Three series of model experiments on the effect of intermediates on isolated proteins - antigens, monoclonal and natural antibodies showed that the introduction of lactate in the antigen-antibody system is more active increasing the time of the onset of agglutination A glycoprotein with the corresponding antibody and reduce the degree of agglutination with natural anti-B antibodies in contrast to preincubation with pyruvate. Apparently, the differences can be explained with the peculiarities of their structure.

\subsection{Visualization of Antigen-Antibody Interaction with Lactate Incubation}

Using the method of flow cytometry, effects of pyruvate on the expression of antigenic determinants were revealed (Figure 3). The number of formed immune complexes increased in samples A (II) groups and decreased in $\mathrm{B}$ (III) and AB (IV) blood groups. The next step of our research is the visualization of antigen-antibody using fluorescent probes using laser scanning confocal microscopy. 


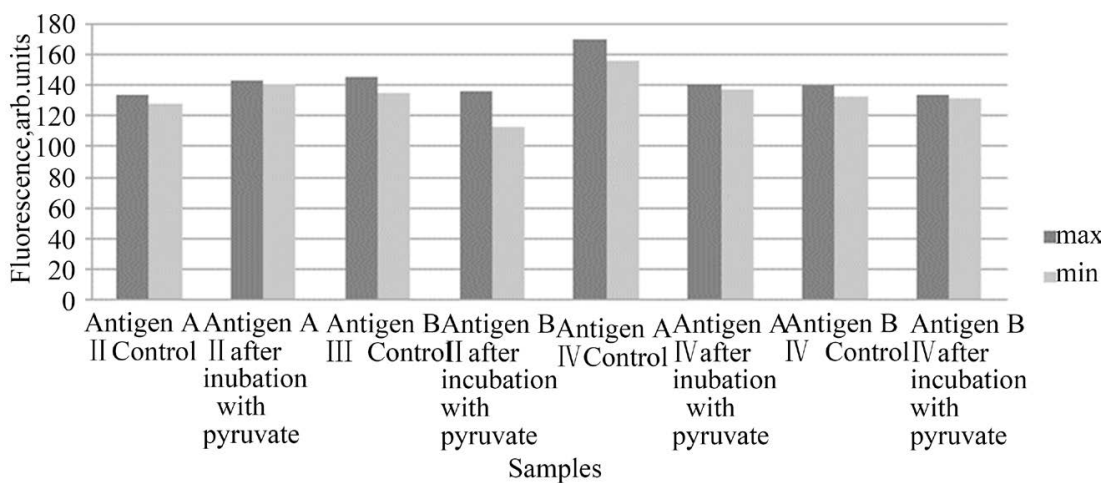

Figure 3. Evaluation of the effect on antigen-antibody interaction of flow cytometry.

Table 1. The effect of minor metabolites on the rate of hemagglutination of erythrocytes of blood groups A (II), B (III), AB (IV).

\begin{tabular}{ccc}
\hline & Lactate $(\mathrm{n}=10)$ & Pyruvate $(\mathrm{n}=10)$ \\
\cline { 2 - 3 } & Mean (time, s) \pm RSD & Mean (time, s) \pm RSD \\
\hline Antigen A A (II) & $8.4 \pm 0.06$ & $7.0 \pm 0.11$ \\
Antigen B B (III) & $7.1 \pm 0.12$ & $6.4 \pm 0.08$ \\
Antigen A AB (IV) & $9.1 \pm 0.09$ & $7.4 \pm 0.07$ \\
Antigen B AB (IV) & $8.1 \pm 0.18$ & $7.4 \pm 0.07$ \\
Control & $5.95 \pm 0.014$ & $5.95 \pm 0.009$ \\
\hline
\end{tabular}

Table 2. The effect of minor metabolites on the efficiency of monoclonal antibody interaction with blood erythrocyte antigens A (II), B (III), AB (IV).

\begin{tabular}{ccc}
\hline & Lactate $(\mathrm{n}=10)$ & Pyruvate $(\mathrm{n}=10)$ \\
\cline { 2 - 3 } & Mean (time, s) \pm RSD & Mean (time, s) \pm RSD \\
\hline Anti-A A (II) & $115.5 \pm 0.03$ & $4.7 \pm 0.10$ \\
Anti-B B (III) & $88.5 \pm 0.07$ & $5.3 \pm 0.09$ \\
Anti-A AB (IV) & $112.5 \pm 0.07$ & $7.0 \pm 0.11$ \\
Anti-B AB (IV) & $88.5 \pm 0.02$ & $6.7 \pm 0.07$ \\
Control & $5.96 \pm 0.011$ & $5.96 \pm 0.011$ \\
\hline
\end{tabular}

Analyzing the spatial distribution of the fluorescence illumination intensity of fluorochrome in the complexes antigen-antibody, we notice a reduction in peak fluorescence in erythrocytes A (II) and (III) blood group after incubation with pyruvate compared with control erythrocytes (Figure 4). Apparently, pyruvate competes for the active reactive group antigens A and B with monoclonal antibodies labeled by fluorescein isothiocyanate, which is reflected in the change of the conformational structure of the protein molecule and the ability of antigens to form complexes antigen-antibody.

\section{Conclusions}

The results obtained by computer prediction show the probability of the pyruvate and lactate influence on intermolecular processes, maintain metabolic balance by regulating protein, carbohydrate, lipid metabolism, antioxidant processes, tissue respiration. The series of experiments clearly showed a more active influence of lactate on protein-ligand interaction of antigen with antibody, in contrast to pyruvate, which is the result of cumulative modifications caused by this metabolite and recorded the speed and completeness of the process of agglutination. 

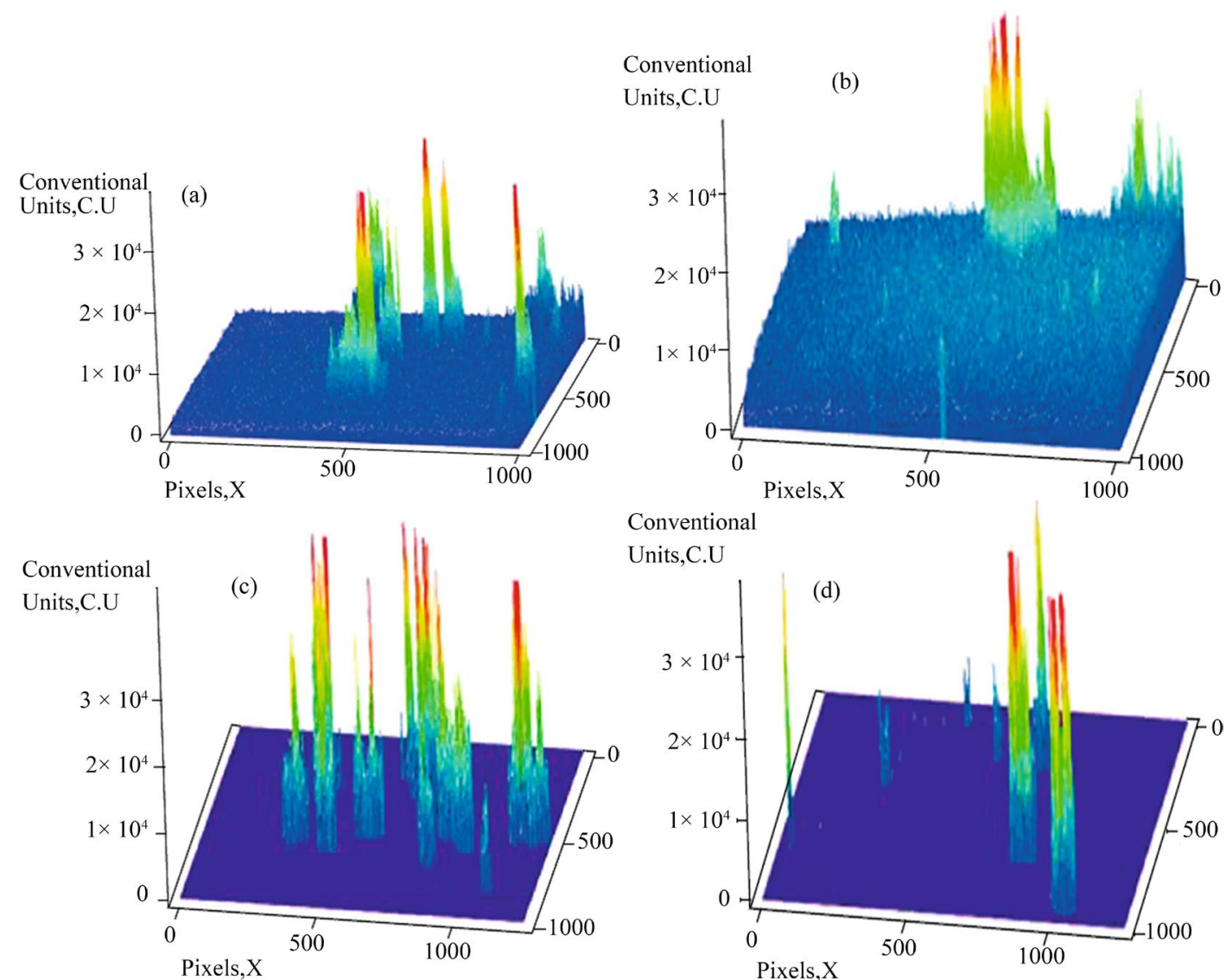

Figure 4. Spatial intensity of FITC fluorescence distribution in antigen-antibody complexes. (a) Control erythrocytes of blood group A (II); (b) Erythrocytes of blood group A (II) incubated with pyruvate; (c) Control erythrocytes of blood group B (III); (d) Erythrocytes of blood group B (III) incubated with pyruvate.

The results indicate the possibility of using natural intermediates, in particular pyruvate and lactate, as a molecular probe and the prospects of the use of glycoproteins A and B, presented on the membrane of red blood cells, as a molecular model for the study of intermolecular interactions.

To summarize, molecular modeling and forecasting allows us to expand fundamental knowledge about the known properties of small molecules and to predict the possible biological effects and molecular mechanisms of their realization in the processes of complex interactions between ligands and their targets.

\section{Acknowledgements}

This work was done on the chair of fundamental and clinical biochemistry with laboratory diagnosis of Samara State Medical University, Russia. This work is supported by the grant in the field of science and technology "Method of visualization of antigen-antibody interactions by confocal microscopy".

\section{References}

[1] Yang, G.X., Li, X. and Snyder, M. (2012) Investigating Metabolite-Protein Interactions: An Overview of Available Techniques. Methods, 57, 459-466. http://dx.doi.org/10.1016/j.ymeth.2012.06.013

[2] Li, X., Gianoulis, T.A., Yip, K.Y., Gerstein, M. and Snyder, M. (2010) Extensive in Vivo Metabolite-Protein Interactions Revealed by Large-Scale Systematic Analyses. Cell, 143, 639-650. http://dx.doi.org/10.1016/j.cell.2010.09.048

[3] Tagore, R.L., Thomas, H.R., Homan, E.A., Munawar, A. and Saghatelian, A.A. (2008) Global Metabolite Profiling Approach to Identify Protein-Metabolite Interactions. Journal of the American Chemical Society, 29, 130. http://dx.doi.org/10.1021/ja806463c

[4] Li, X. (2013) Systematic Investigation of Protein-Small Molecule Interactions. IUBMB Life, 65, 2-8. 
http://dx.doi.org/10.1002/iub.1111

[5] Lomenick, B., Olsen, R.W. and Huang, J. (2011) Identification of Direct Protein Targets of Small Molecules. ACS Chemical Biology, 6, 34-46. http://dx.doi.org/10.1021/cb100294v

[6] Gilmiarova, F.N. (2014) The Effect of Pyruvate on Antibody Interaction with Group-Specific Erythrocyte Antigens. Biomedical Chemistry, 8, 260-265. http://dx.doi.org/10.1134/s1990750814030056

[7] Rogatzki, M.J. (2015) Lactate Is Always the End Product of Glycolysis. Fronties in Neuroscience, 9, 1-7. http://dx.doi.org/10.3389/fnins.2015.00022

[8] Schurr, A. and Gozal, E. (2012) Aerobic Production and Utilization of Lactate Satisfy Increased Energy Demands upon Neuronal Activation in Hippocampal Slices and Provide Neuroprotection against Oxidative Stress. Frontiers in Pharmacology, 2, 96.

[9] Schurr, A. and Gozal, E. (2015) Glycolysis at 75: Is It Time to Tweak the First Elucidated Metabolic Pathway in History? Frontiers in Pharmacology, 15, 170. http://dx.doi.org/10.3389/978-2-88919-586-2

[10] Kane, D.A. (2014) Lactate Oxidation at the Mitochondria: a Lactate-Malate-Aspartate Shuttle at Work. Frontiers in Pharmacology, 25, 366. http://dx.doi.org/10.3389/fnins.2014.00366

[11] Brooks, G.A. (2002) Lactate Shuttles in Nature. Biochemical Society Transactions, 30, 258-264. http://dx.doi.org/10.1042/bst0300258

[12] Patent for Invention No. 2484480 Dated 10-06-2013.

[13] Gylmiyarova, F.N., Radomskaya, V.M. and Gergel, N.I. (2007) Blood Groups: Biological Variability of Cells and Metabolism in Norm and Pathology. Izvestiya, Moscow.

[14] Marsh, W.L. (1972) Scoring of Hemoagglutination Reaction. Transfusion, 12, 352-353. http://dx.doi.org/10.1111/j.1537-2995.1972.tb04459.x

[15] Filimonov, D.A., Lagunin, A.A., Gloriozova, T.A., Rudik, A.V., Druzhilovskii, D.S., Pogodin, P.V. and Poroikov, V.V. (2014) Prediction of the Biological Activity Spectra of Organic Compounds Using the Pass Online Web Resource. Chemistry of Heterocyclic Compounds, 3, 483-499. http://dx.doi.org/10.1007/s10593-014-1496-1

[16] Yarcev, V.N. (2014) Paradoxical Acidosis Effects on the Neurogenic Tonus of the Blood Vessels in Hypothermia. Biomedical Radioelectron, 4, 84-85.

[17] Zhirnov, O.P. (2014) pH-Dependent Rearrangements in the Virus Structure. Questions of Virusology, 59, 41-46.

\section{Submit or recommend next manuscript to SCIRP and we will provide best service for you:}

Accepting pre-submission inquiries through Email, Facebook, Linkedin, Twitter, etc A wide selection of journals (inclusive of 9 subjects, more than 200 journals)

Providing a 24-hour high-quality service

User-friendly online submission system

Fair and swift peer-review system

Efficient typesetting and proofreading procedure

Display of the result of downloads and visits, as well as the number of cited articles

Maximum dissemination of your research work

Submit your manuscript at: http://papersubmission.scirp.org/ 